\title{
A DISCUSSION OF HUMAN AND INSECT SOCIETIES
}

\section{By Milton F. CROWell}

In considering insect and human societies together we face several problems. 1. What is a society? 2. By what methods do insects and men solve the problems of a social life? 3. Is there any reason to believe that, if human and insect societies differ, they may, eventually, evolve into the same type?

To define a society in terms that will permit the inclusion of both insects and men, and exclude animals not usually regarded as social, is well-nigh impossible, but the following definition is suggested: A society is a group of organisms of the same species in which specific survival is dependent upon association in a group; the characteristics of the group as a unit differ from those arising as a mere sum of its individual parts; the functions of the group necessary for its existence, therefore necessary for the survival of the species, are carried out by a division of labor among the individuals of the group; the successful carrying out of these functions is dependent upon the ability of the group to exploit a given area, or trophoporic field. As a corollary to this definition, implied, but not specifically stated in it, a society must be self-perpetuating.

The problems of social life are contained in definition of society, and they over-lap.

1. The creation of the group.

2. The maintenance of the group.

a. The re-creation of the group.

b. Provision of food and shelter.

(1). Exploitation of the trophoporic field.

c. Defence of the group. 
3. The perpetration of the group.

a. Dependent upon the effectiveness with which the group is maintained.

In neither man nor insects can we speak of the creation of the group in the strict sense. The groups, or societies, are being constantly re-created, or perpetuated. In the insect society perhaps, we come nearer to society creation, for, regarding each colony as a separate society, it is begun, in the termites, when a male and female start a new nest; in the ants, when, by various methods, a fertilized female succeeds in founding a colony, and in the bees, when a swarm occurs. But in most instances, even here, there is a mixing of colonies, since in the nuptial flights of social insects a certain amount of cross-breeding takes place, i.e., between males and females of different colonies, so we can, to a certain extent, regard insect society as being much broader than the single colony.

The problems of maintenance and perpetuation are, to a great degree, the same. In order to provide food and shelter there must be a sufficient number of individuals to carry out the work of provision. In order to have a sufficient number of individuals to provide for the group, food and shelter must be efficiently supplied. Since both the production of offspring and the provision of food are necessary to maintain a society it is fruitless to discuss which is the more important.

In reproduction we find that there are two general methods found in the various types of societies. Both are effective, and each is apparently the best for the society in which it is found. There may be developed a special machinery for reproduction, i.e., a reproductive caste, whose contribution to the community is solely offspring. Or we may have no special reproductive caste, but the production of a few offspring by each, (or as is actually the case, by most), of the group units. (Group units, in speaking of reproduction in higher animals, are obviously not individuals, but are composed of two individuals of the opposite sex.)

The first type produces numerous large families which, 
to a great extent, form separate homogeneous societies. The second type produces a looser heterogeneous society of which separate families are but the basic units. The insect society depends upon large numbers of offspring produced by individual females; the human society depends upon a large number of females producing few offsprings. This distinction is primarily biological, hence fundamental.

There are two ways in which large numbers of offspring can be produced by a single female. One is by the overdevelopment of the ovaries, and the laying of a great number of eggs. (Queen of Termes bellicosus; "she has laid an egg every three minutes for the past four years," Wheeler, 1928, a total of almost a million $)^{1}$; the queen honey-bee, Apis mellifica, lays about 3500 eggs a day for several weeks at the height of the breeding season, Langstroth, 1909. The second is by polyembryony, or the development of several offspring from the same egg. This is found in a number of the higher hymenoptera. (Aphelopus theliae, whose single egg produces 40-60 offspring, according to Kornhauser, 1919; Copsidosoma gelechiae, Paracopidosomopis floridanus, Platygaster sp., the first with over 300, the second averaging over 1000, and the last 5-36 offspring, which Patterson, 1919, believes may develop from single eggs.)

The method of foetal development in the placental mammals makes impossible the production of offspring in great numbers by a single female. Both the limits of space, (the size of the uterus,) and the limits of time, (length of life compared with time necessary for foetal development), place decided limits to the possible number of offspring. So it seems clear that, basically, human and insect societies can never be physically homologous.

In solving the problems of maintenance by the provision of food and shelter both human and insect societies exploit a trophoporic field. This field is the actual territorial area

1E. Hegh, 1922, in "Les Termites," says of T. bellicosus, "qui, d'apres Smeathman et Escherich, serait d'au moins trente mille par jour, soit dix millions par an et cent millions pour la duree probable de la vie de la reine." I do not understand this disagreement of authorities, but an egg every three minutes is 20 an hour, and thus only 480 a day. In either case, a large number of eggs is laid. 
which supplies the raw materials of food and shelter building. While there is a fundamental difference between the methods used by men and insects to re-create the group, the methods used by each to exploit the trophoporic field do not differ fundamentally. There are two methods used: the actual collection from the field of the materials needed (in the insects by foraging for what can be found), by development, as the growth of fungi and the "domestication" of aphids by ants; in man, foraging, (not common), and development, (farming, mining, etc.), and the taking by force of the materials collected by other groups. The second method is dependent upon the first, and is essentially nonsocial when it means the exploitation of parts of a society by other parts. Of course, one society may legitimately become a part of the trophoporic field of another, as the keeping of bees by man, or the eating of a library by termites. (There is no reason, from a termite point of view, for respecting the possessions of man). And in each society, human and insect, the exploitation of the trophoporic field is possible only by labor on the part of the individuals of the society.

Since the many activities necessary for efficient production can be carried out best by a specialization for particular tasks among the members of a society we find that there is a division of labor developed by both insects and men. The first most fundamental division of labor is, of course, the development of sex. This is found in both groups. But, as pointed out before, the insects have developed a special caste that does nothing but reproduce, while man has not. In the exploitation of the trophoric field, too, the insects have developed a caste, which has, to a great degree, lost its ability to reproduce, the worker caste. This sterile caste does all of the labor necessary for producing food, building the nest (except in the case of some insects where the primal sexual pair, or a single fertilized female, initiates the work of nest building), caring for the reproductive caste (whose children they are), and caring for the new brood (their brothers and sisters). This division of labor has brought about an actual structural difference between the reproductive and worker castes, 
and in many instances, specialization to tasks performed has caused the development of structural differences among the workers themselves. This is termed polymorphism.

The differentiation of sexes is a form of polymorphism, and it would be admissible to speak of a male and a female caste, but that is as far as caste and polymorphism in any way homologous to that of insects has been carried in man. Since in a society which is based upon a grouping of small families $^{1}$ the production of offspring falls upon all, it follows that in order to maintain and perpetuate the society there cannot be present in it a large percentage of sterile individuals. Also, in that type of society, there cannot be any great degree of polymorphism, for the forming of numerous families implies the necessity for a wide range of possibility to mate. There is also the implication that any member of this society shall be able to carry on any function of the group. This may not seem evident at first glance, but human society is a conglomeration of numerous small societies, i. e., families, and because of the type of foetal development in the placental animals, and the period after birth during which the young are dependent, the maintenance of the family falls upon the adult members, and they cannot become so specialized that they cannot perform any one of the functions necessary for maintenance. Hence, if they must remain generalized with regard to the family, they must remain generalized with regard to society, which is but a group of families. (This refers only to morphological specialization). Therefore it follows that the division of labor in the exploitation of the trophoporic field is, in man, brought about in a manner fundamentally different from that of the insects. It is not a specialization, in the biological sense, but is a development of one or more generalized abilities possessed in varying degrees by all members of the group. Therefore the laboring class, the

1The human family, no matter how large it may be, is, of course, a small one. This is evident when we consider that, at the utmost, one woman could bear only about 30 children, while a family of social insects may number well over a million individuals all produced by one female. 
capitalistic class, and the castes of India, are not homologous to the castes of insects.

There are at least two classes of human beings that might be considered as being somewhat analogues to the workers of the termites, or higher ants: the priests of many religions, and the eunuchs of Eastern countries. The priest, in so far as he represents a sterile class, sterile through voluntary celibacy, is an example of a non-reproducing individual laboring for the good of the organization to which he belongs. (Not necessarily for the good of society). The eunuch is functionally sterile, and thus approaches nearer an analogy to the insect worker. And if the interpretation of polymorphism of the social insects which holds that the differentiation of the castes is caused by giving different food to the larvae that are destined to develop into different forms be correct, the difference between the ennuch of the harem and the worker insect becomes still less. Both are then products of a deliberate castration, whether it be a reasoning and purposive act, or a blind instinctive reaction governed by the needs of the insect colony.

But the likness of the priest and eunuch to the worker insect is more apparent than real. Although the priest may be socially sterile he is not functionally so, and he is not morphologically set apart for the performance of certain duties. And while the eunuch is, of course, sterile, his sterility is not the result of the necessity of society to have a group of workers who will have their labors uninterrupted by the functions of reproduction, but is to prevent his having sexual connection with the women of his master's household.

While the exploitation of the trophoporic field by a society requires many laborers, and the problem has been solved in man and in insects by two methods of reproduction (a great number of offspring produced by one female, and a great number of females each producing a few offspring) man has added a second method of producing workers, that is by the invention and development of machinery. The machine either greatly increases the efficiency of the individual worker, or greatly multiplies him by doing what many men would be required to do. In being 
sterile, (physiologically), and in being able to accomplish only a special task, the machine is nearer to the insect worker than is any class of men. Genetically, of course, it is not even analogous to the insect. The introduction of the machine, on the one hand, and the development of the highly specialized worker on the other, has forced both men and insects to face the problem of what to do with individuals that the machine, or the accomplishment of a special function, has deprived of work. The insects have solved it. When the work of the specialists is done they are slaughtered. When the introduction of a new machine deprives a number of men of work . . . the problem has not been solved.

Besides maintenance by the exploitation of the trophoporic field the society must be maintained against destruction by the elements, broadly, climate, and destruction by other societies, sub-groups of itself, (nations, different colonies), and against the attacks of other organisms, (beasts of prey, disease germs, etc.).

The primary method of defense is flight; next comes the building of shelters. The ants and termites construct caverns, the wasps build houses, i. e., paper nests, etc. Man's shelters differ little fundamentally from those of insects. Advantage is taken of natural shelters, caves, comparable to the use of hollow trees by bees, or houses are built, comparable to wasps' nests. Shelters are employed as a means of defense against all types of attack.

A more active method found in both insect and men is the development of special classes for defensive purposes, "soldiers" in the ants, termites; soldiers, policemen, etc., in human society. There is the same distinction between the human soldier and the insect soldier that is found between the human worker and the insect worker. One is a specialized organism, the other is a generalized organism in which certain abilities are specialized. An insect soldier can be only a soldier, really a specialized worker, but a human soldier may be a soldier temporarily, and is not forced by his morphology to be one whether or no.

The last problem of a society, and perhaps the first, perpetuation has already been discussed. Its successful ac- 
complishment depends entirely upon the success with which the group is maintained.

The possibility of the insect and human types of society becoming identical was the third question asked at the beginning. The two societies face the same problems, and in some instances their methods of solution are the same. But in the development of the means by which these methods are carried out the two societies are different. In the discussion of the methods by which the two societies are re-created, and the workers developed, the points of difference were stated. And there it was brought out that the two types of society are not homologous. The fundamental difference, and one which is insurmountable, is the difference between the Hexapods and the Placentalia.

\section{Literature.}

Wheeler, W. M.-Foibles of Insects and Men: The Termitodoxa, or Biology and Society. Alfred A. Knopf, New York, 1928.

Hegh, E.-Les Termites: Partie Generale. Brussels, 1922. Langstroth, L. L.-Langstroth on the Hive and Honey Bee. 20th Cent. Ed. pp. iii-275, 229 fig. Dandant \& Son, 1909.

Kornhauser, S. I.-The Sexual Characteristics of the Membracid Thelia limaculata (Fabr.) I. External changes induced by Aphelopus thelize (Gahan). Jour. Morph. vol. 32. pp. 531-635, 54 fig. 1919.

Patterson, J. T.-Polyembryony and Sex. Jour. Heredity, vol. 10, No. 8. pp. 344-352, 9 fig. Nov. 1919. 

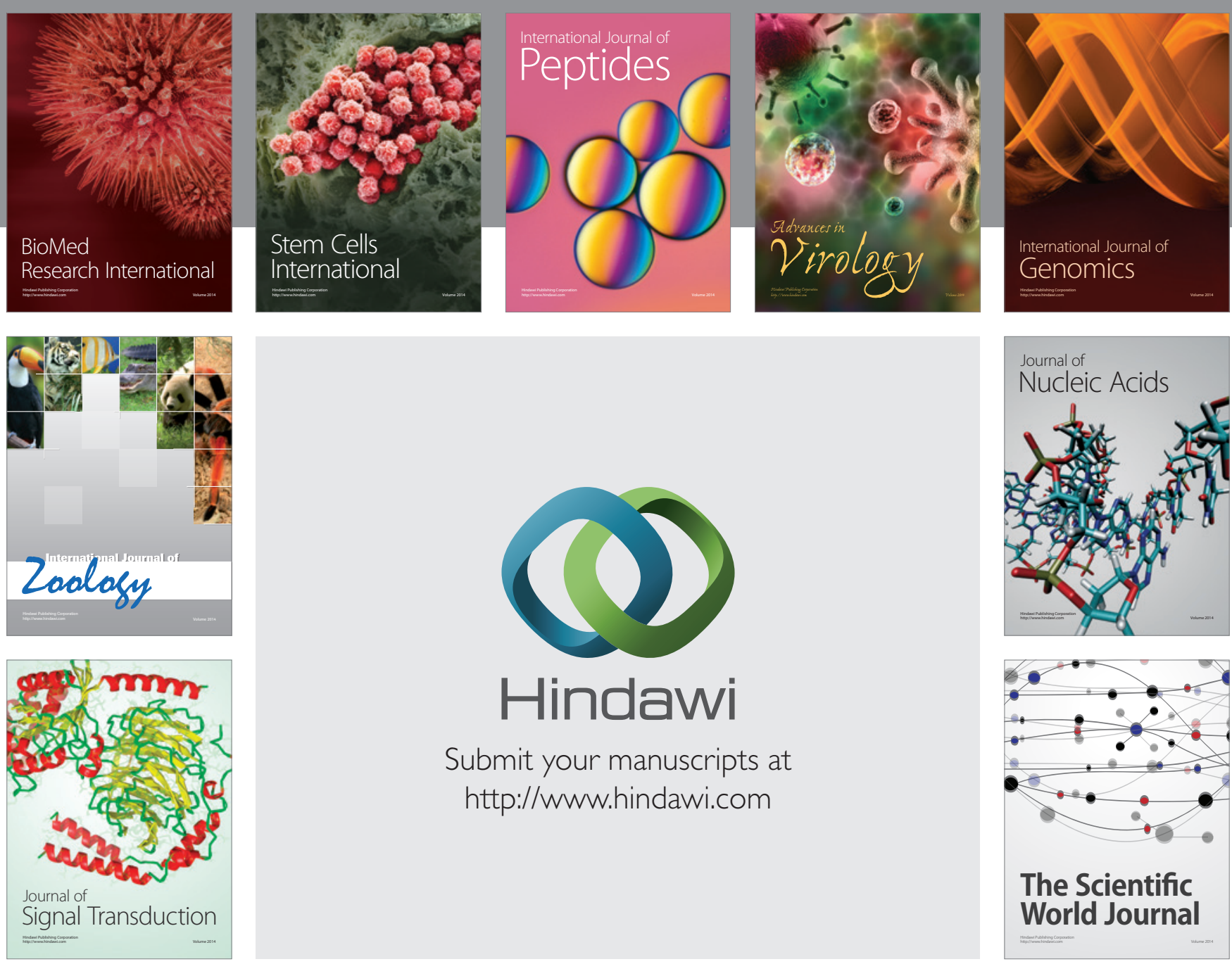

Submit your manuscripts at

http://www.hindawi.com
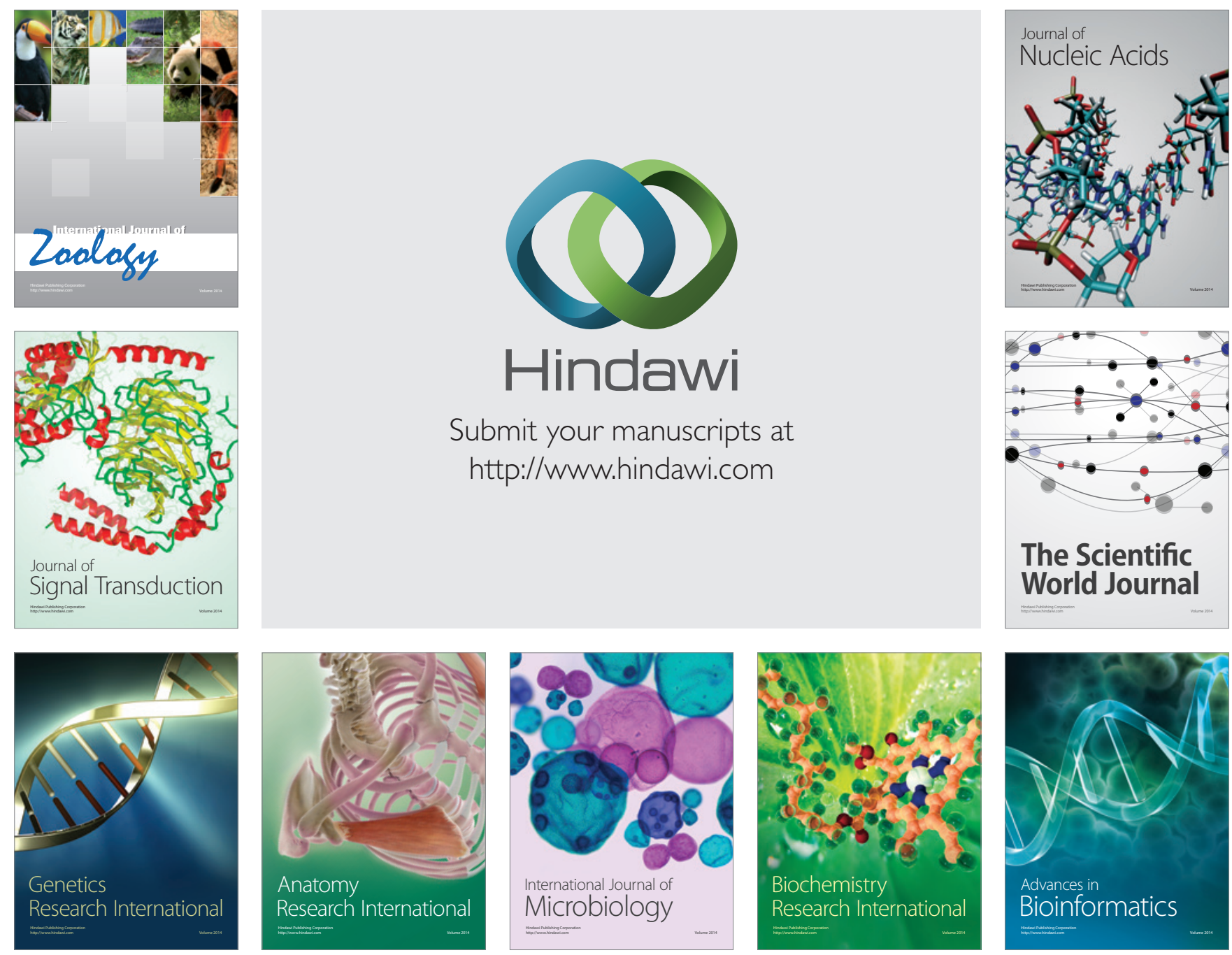

The Scientific World Journal
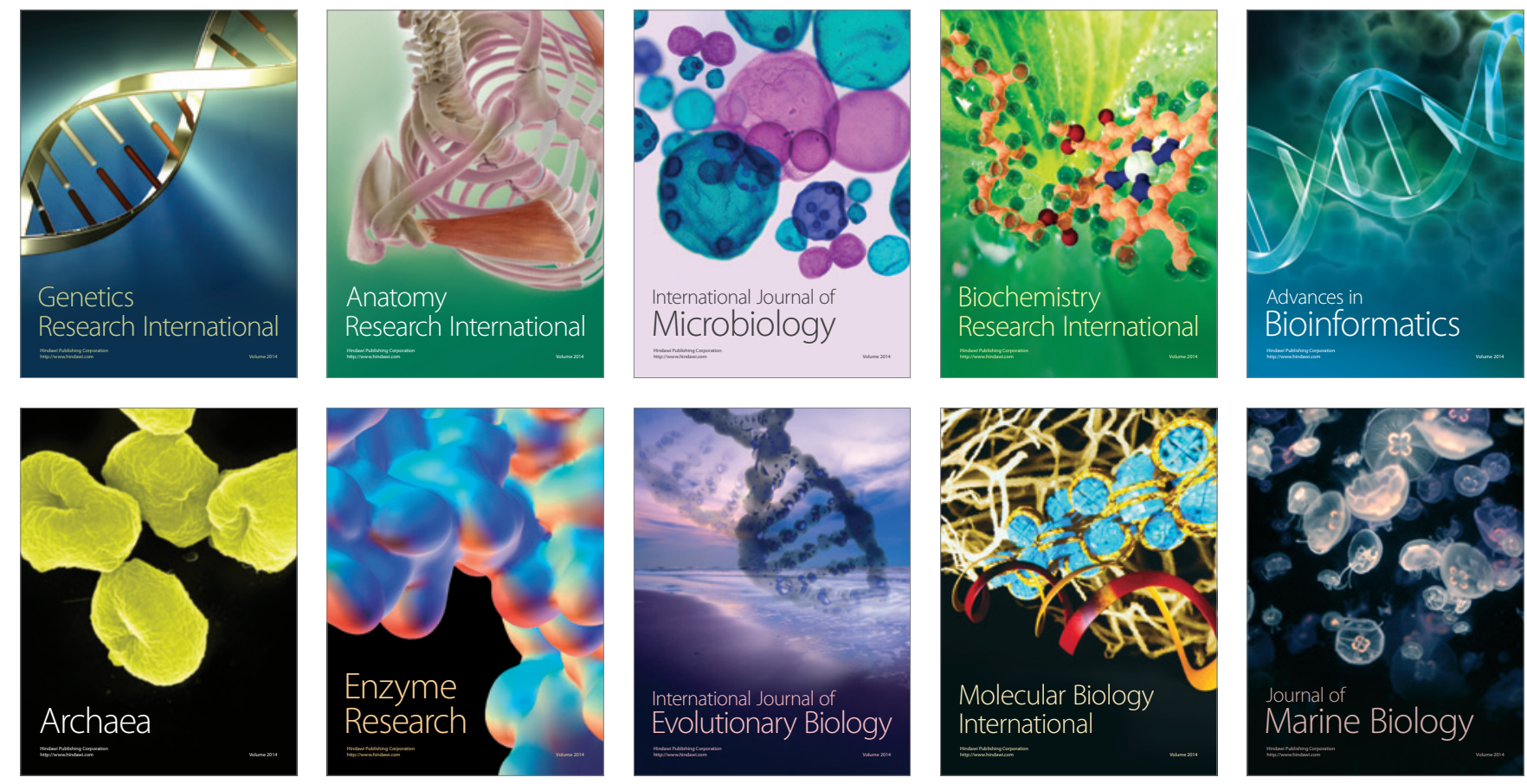